\title{
Study of heterogeneous vertical hyporheic flux via streambed temperature at different depths
}

\author{
JINGSI ZHU1, LONGCANG SHU ${ }^{2}$, CHENGPENG LU², JUNJIANG LI ${ }^{2}$, \\ SHUAI CHEN ${ }^{2}$, SHULEI LI ${ }^{2}$ \& GUAN WANG ${ }^{2}$ \\ 1 Hydrology Bureau of Haihe River Water Conservancy Commission, MWR, Tianjin, 300170, China \\ 2 College of Hydrology and Water Resources, Hohai University, Nanjing, 210098, China \\ luchengpeng@hhu.edu.cn
}

\begin{abstract}
The hyporheic flux can be characterized using the heat-tracing method. Based on the analytical solution of the one-dimensional steady-state heat transport equation under vertical groundwater discharge conditions, hyporheic flux was obtained via a curve fitting method. The temperature data used was obtained from monitoring three different sections of the DaWen River, Shandong Province. The distribution of the depth of the hyporheic zone was analysed by a curve relating groundwater temperature and the depth of the hyporheic zone. The study results showed that the vertical hyporheic flux was significantly heterogeneous along the three sections. The hyporheic flux ranged from 99.61 to $356.25 \mathrm{~L} / \mathrm{m}^{2}$ per day. In the summer, the low temperature area on streambed profile was in accordance with the high value areas of hyporheic flux. There were several strong discharge zones within the same section and these flux values were normally distributed. The depth of the hyporheic zone was inversely proportional to the hyporheic flux and the hyporheic zone depth, also, presented great spatial heterogeneity.
\end{abstract}

Key words hyporheic flux; heterogeneity; heat transport equation; temperature profile; hyporheic zone depth

\section{INTRODUCTION}

As the interaction and transition zone of surface water and groundwater, the hyporheic zone plays an important role in the hydrological cycle (Brunke and Gonser 1997). Hyporheic exchange affects the constitution of water resources along the riverbank and ecological function of the transformation interface between river and groundwater (Wang et al. 2007). Having a clear understanding of the processes and characteristics of hyporheic exchange is of great significance in evaluating and exploiting water resources, as well as for maintaining and restoring the surface water-groundwater ecological system. Hydraulic characteristics of natural aquifer media have significant heterogeneity and spatial variability.

Research methods for hyporheic exchange flux include direct measurement, methods based on Darcy's laws and mass balance approaches (Kalbus et al. 2006). In recent years, the heat tracing method has become popular due to rapid development of temperature measurements in simulation methods. The heat tracing method involves burying a thermometer down a borehole or in waterbearing media to obtain continuous observed data that reveals the characteristics of water flow movement and heat transportation; hence, the hyporheic flux can be achieved easily, rapidly and accurately. The heat tracing method can be applied in analysing exchange of hyporheic flux, recharge and discharge rates from interactions between surface water and hydraulic conductivity of streambed sediments (Anderson 2005). Conant (2004) and Schmidt et al. (2006) measured the temperature profiles at specific depths of a streambed and calculated groundwater discharge. However, there is little accurate depiction and quantitative analysis of the heterogeneity characteristics of hyporheic flux in existing studies (Hatch et al. 2006, Ferguson 2007, Lautz et al. 2010), and the depth of the hyporheic zone is rarely mentioned.

This study, therefore, monitored the streambed temperature of DaWen River, which is a typical natural river in the Wenshang County of Shandong Province. The heterogeneity characteristics of the general hyporheic exchange process of this streambed was analysed by means of the heat tracing method. Also, spatial distribution patterns of the hyporheic flux and hyporheic zone depth were analysed.

\section{METHODS OF HYPORHEIC FLOW CALCULATION}

The basic assumption is that surface water and groundwater mainly exchange vertically within the riverbed. The governing equation for one-dimensional steady-state heat transport in the saturated 
porous media (Bredehoeft and Papadopolus 1965) is:

$$
\frac{K_{f s}}{g c} \tilde{\mathbf{N}}^{2} T(z)-\frac{g_{f} c_{f}}{g c} \tilde{\mathrm{N}} \times\left(T(z) q_{z}\right)=\frac{\mathbb{T} T(z)}{\mathbb{\prod} t}
$$

where $T(z)\left[{ }^{\circ} \mathrm{C}\right]$ is the streambed temperature at depth $z ; t[\mathrm{~s}]$ is time; $q_{z}[\mathrm{~m} / \mathrm{s}]$ is vertical hyporheic flux, which is the hyporheic flux; $r c\left[\mathrm{~J} /\left(\mathrm{m}^{3} \cdot \mathrm{K}\right)\right]$ is the volumetric heat capacity of the solid-fluid system given as $r c=n r_{f} c_{f}+(1-n) r_{s} c_{s}$ where $r_{f} c_{f}$ is the volumetric heat capacity of the fluid and $r_{s} c_{s}$ is the volumetric heat capacity of the solids; $n$ [-] is the porosity; and $K_{f s}[\mathrm{~J} /(\mathrm{s} \cdot \mathrm{m})]$ is the thermal conductivity of the saturated sediment.

If the upper and lower boundary conditions are $T=T_{0}$ for $z=0$, and a fixed temperature $T_{L}$ for $z=L$, where $L$ is the depth of the hyporheic zone, the solution for equation (1) can be obtained:

$$
\frac{T(z)-T_{0}}{T_{L}-T_{0}}=\frac{\exp \left(-\frac{q_{z} g_{f} c_{f}}{K_{f s}} z\right)-1}{\exp \left(-\frac{q_{z} g_{f} c_{f}}{K_{f s}} L\right)-1}
$$

where $T_{0}$ is the temperature of the surface water and $T_{L}$ is the temperature of the groundwater. The range of $K_{f s}$ is 1.4 to $2.2 \mathrm{~J} /(\mathrm{sm})$. $K_{f s}$ was set to $2.0 \mathrm{~J} /(\mathrm{sm})$ and $r_{f} \mathcal{c}_{f}$ is equal to $4.2 \times 10^{6} \mathrm{~J} /\left(\mathrm{m}^{3} \cdot \mathrm{K}\right)$, cited by Stonestrom and Constantz (2003).

The measured temperature of every vertical line varies with depth and satisfies:

$$
T(\mathrm{z})=c+a \times \exp (-b \times z)
$$

where $a, b$ and $c$ are unknown parameters. Through minimizing the sum of the squares of deviations between the measured and calculated temperatures via the curve fitting, the parameter $q_{z}$ and $T_{0}$ of each line on the profile can be obtained. The process of curve fitting was accomplished using a Matlab code.

\section{IN SITU TEMPERATURE MONITORING}

\subsection{Weather, hydrological and geological conditions}

The test site is located in the DaWen River of Wenshang County in Jining City, Shandong Province, at about $2 \mathrm{~km}$ distance from the dam of the PiPa Mountain (Fig. 1). The type of climate in the DaWen watershed is from semi-humid to temperate continental monsoon. The average annual temperature is $12.9^{\circ} \mathrm{C}$ and the average annual rainfall is $694.0 \mathrm{~mm}$. Most of the precipitation rains during the flood period. Runoff mainly occurs during the flooding period, with over $80 \%$ generated between June and September. Natural runoff is quite scarce in the dry season and therefore, most of the river segments tend to dry out. The streambed sediments were, mostly, composed of gravel from the grain size analyses tests.

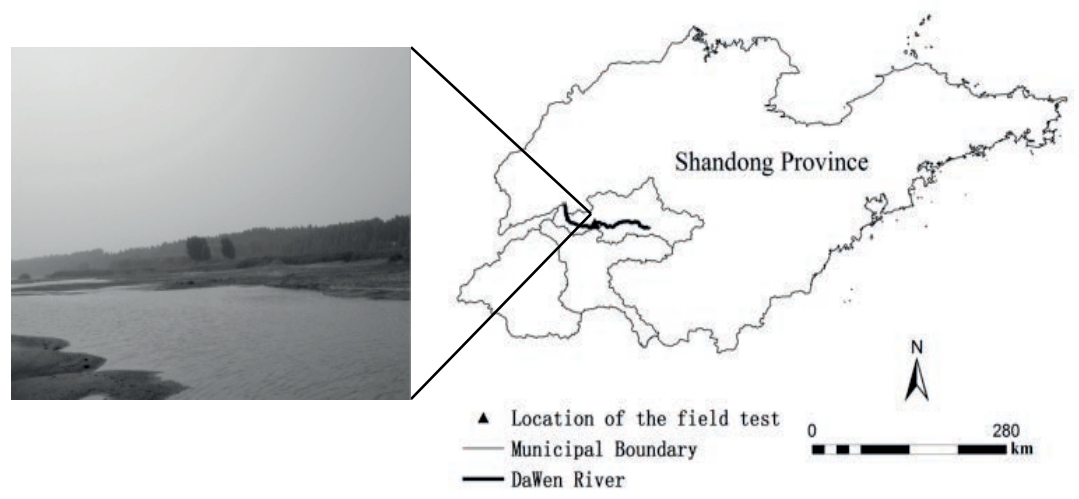

Fig. 1 Location of the test site in Shandong Province. 


\subsection{Schedule of streambed temperature monitoring}

The in situ temperature monitoring was conducted from 4th to 7th June 2012. The thermodetector used for the test is made up of a probe, a thermometer and a sensor. Three sections were investigated on the south bank of the river. The space between each profile was $25 \mathrm{~m}$. Sections A, $\mathrm{B}$ and $\mathrm{C}$ ranged from east to west along the river. Figure 2 shows the location of the test profiles and the distribution of monitoring points in one test profile. The space between each vertical line was $0.1 \mathrm{~m}$, and five points were measured at each vertical line at an interval of $0.1 \mathrm{~m}$. Owing to the small variation of water temperature, a steady temperature field was obtained at each section.

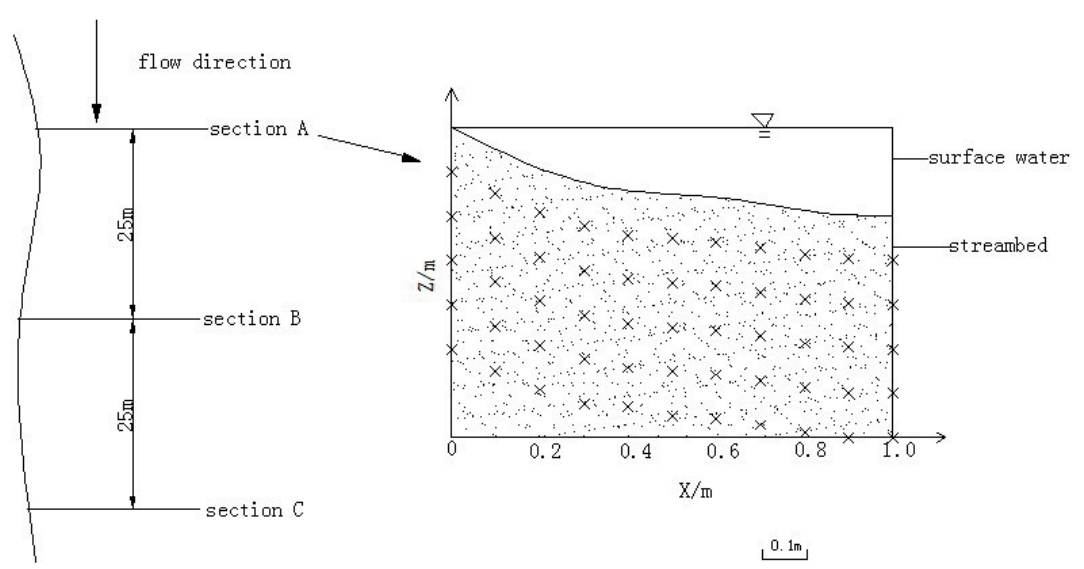

Fig. 2 Location of the test sections and the distribution of sampling points.

\section{RESULTS AND DISCUSSION}

\subsection{Streambed temperature profile}

Figure 3 shows the temperature profiles of sections A, B and C. The $x=0 \mathrm{~m}$ is the interface of the river and bank. The horizontal measurement range is $1 \mathrm{~m}$ for profiles $\mathrm{A}$ and $\mathrm{C}$, and $1.4 \mathrm{~m}$ for profile $\mathrm{B}$. The streambed temperatures of the three profiles ranged between 22.5 and $28.7^{\circ} \mathrm{C}$. The
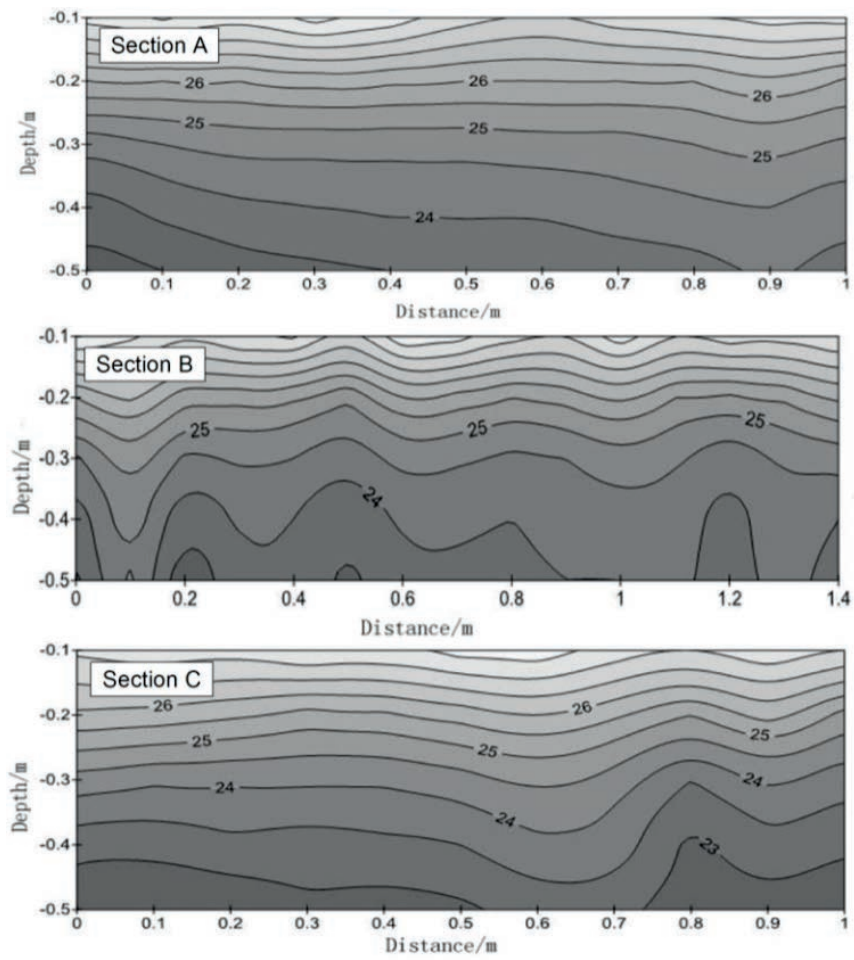

Fig. 3 Temperature profiles $\left({ }^{\circ} \mathrm{C}\right)$ for the sections A, B and C. 
temperature of profile B below $0.3 \mathrm{~m}$ from the streambed had high variability. The fluctuation tendency of streambed temperature was markedly different at 0.8 to $1 \mathrm{~m}$ from the bank of the river (Fig. 3). The gradient of temperature in each profile reduced gradually from the top to bottom of the streambed, illustrating that the deeper the streambed depth, the more stable the temperature.

In summer, major groundwater discharge zones are indicated by relatively low streambed temperature (Schmidt et al. 2006). The first and second discharge zones were located at between 0.2 to $0.5 \mathrm{~m}$ and 1.1 to $1.3 \mathrm{~m}$ in profile $\mathrm{B}$.

\subsection{Hyporheic exchange flux}

The calculated flux was positive (Fig. 4), indicating that the flow direction is upward. Four comparisons of the observed and fitted results for the maximum and minimum hyporheic flux are presented in Fig. 4. When the hyporheic flux is larger, the temperature converges more rapidly with the depth. In other words, the larger the hyporheic flux, the shorter the distance from the streambed surface to the location with stable temperature.
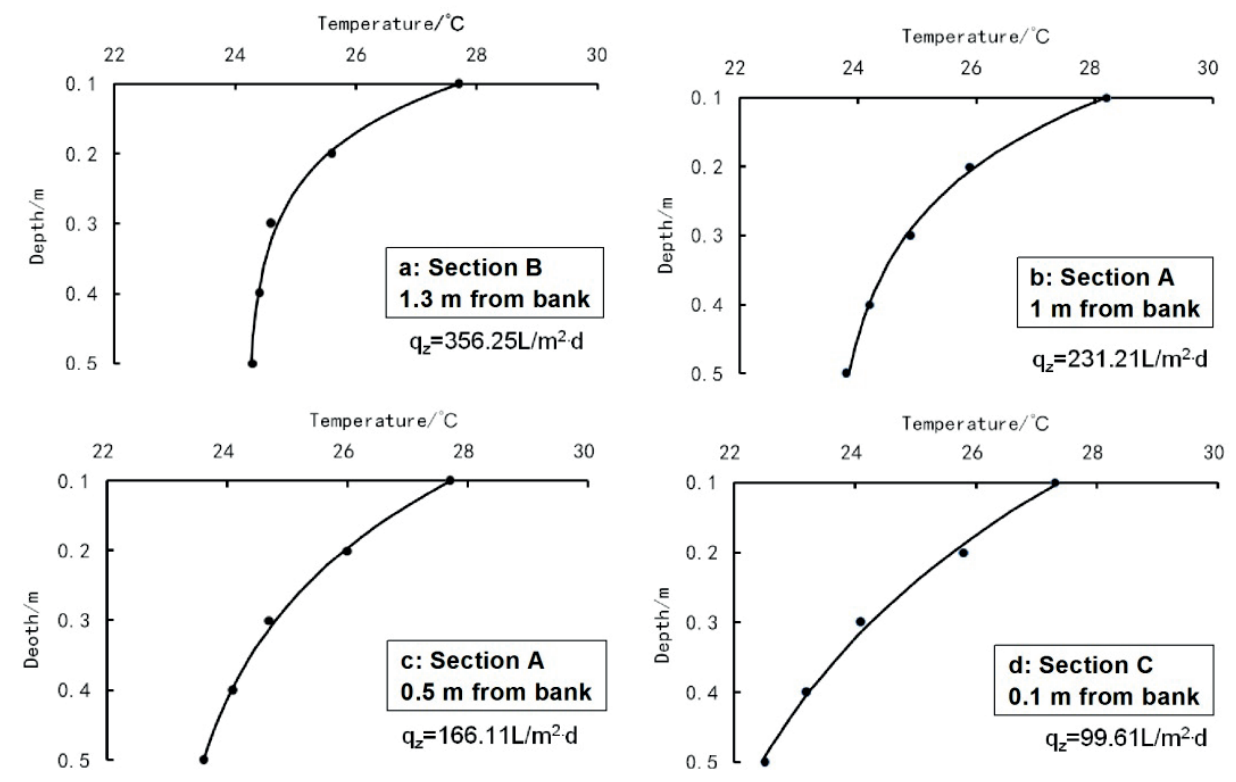

Fig. 4 Curve fitting of measured temperature at the test site.

Table 1 summarizes the statistical characteristics of the hyporheic flux. The mean value was $213.23 \mathrm{~L} /\left(\mathrm{m}^{2} \cdot \mathrm{d}\right)$ and ranged from 99.61 to $356.25 \mathrm{~L} /\left(\mathrm{m}^{2} \cdot \mathrm{d}\right)$. The maximum value was 356.25 $\mathrm{L} /\left(\mathrm{m}^{2} \cdot \mathrm{d}\right)$ at $1.3 \mathrm{~m}$ distance from the bank of profile $\mathrm{B}$, while the minimum was $99.61 \mathrm{~L} /\left(\mathrm{m}^{2} \cdot \mathrm{d}\right)$ at $0.1 \mathrm{~m}$ from the bank of profile C. In general, $50 \%$ of the total hyporheic flux ranged between 70 and $210 \mathrm{~L} /\left(\mathrm{m}^{2} \cdot \mathrm{d}\right)$. Samples of all and each of the profiles were normally distributed via a nonparameter single sample test.

The different profile distributions of the hyporheic fluxes are plotted in Fig. 5. Three high discharge zones ranging between 0.3 to $0.5 \mathrm{~m}, 0.7$ to $0.9 \mathrm{~m}$, and 1.1 to $1.3 \mathrm{~m}$ were confirmed as the major discharge zones from streambed temperature (Fig. 3). The hyporheic flux increased slightly from the bank to the river with high variability. The hyporheic flux varies with the quantity of flow, gradient, streambed topography, permeability of sediment and slope of the river (Harvey and Bencala 1993). The spatial variability is influenced by the heterogeneity of hyporheic zones under conditions of little change in topography and steady flow at one site. The homogeneous streambed might lead to less significant preferential flowpaths and, thus, lower maximum fluxes. Therefore, the more remarkable heterogeneity has a bigger flux (Schmidt et al. 2006). 
Table 1 Hyporheic flux distribution statistics in the three sections.

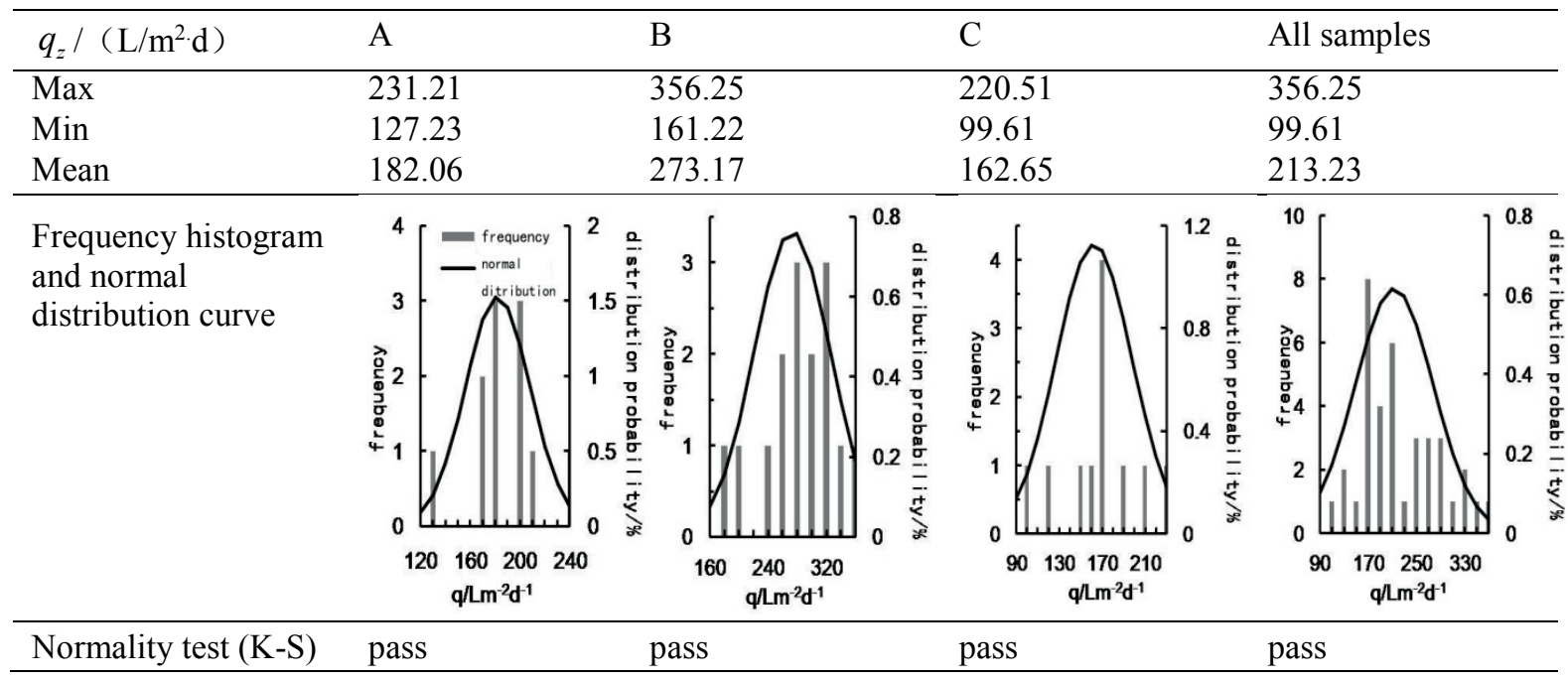

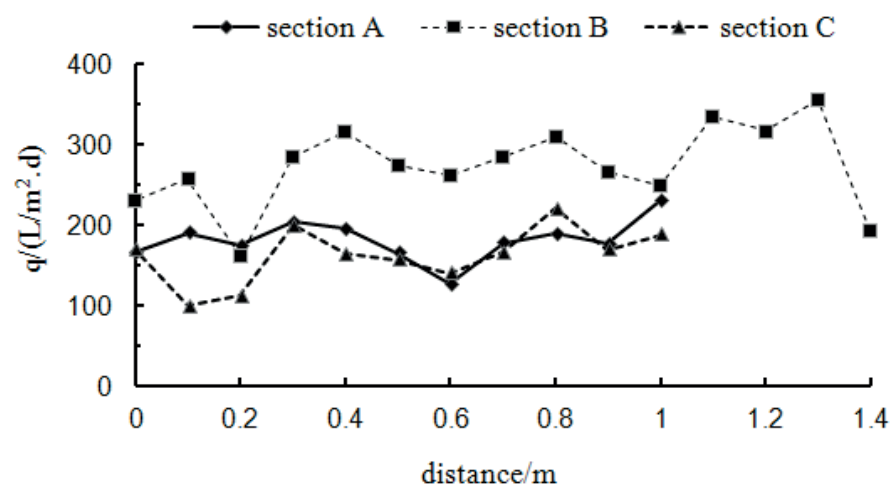

Fig. 5 Hyporheic flux distribution of the different sections.

\subsection{Temperature of groundwater and the depth of hyporheicflux zone}

Generally, large hyporheic fluxes occur in places where connectivity between the surface water and groundwater is good, indicating that the depth of hyporheic flux was smaller. As illustrated in Fig. 6, the temperature of streambed attenuated rapidly under the surface of the streambed, within $1 \mathrm{~m}$, and then become steady. The gradient of groundwater temperature was set to 0.01 and 0.001 ${ }^{\circ} \mathrm{C} / \mathrm{m}$, respectively. Determining the depth of the hyporheic zone was based on an increased sequence arrangement of groundwater temperature and joining the points smoothly. The depth of hyporheic zone was indicated by mean values of 1.65 and $2 \mathrm{~m}$ from the two temperature gradients. The minimal depth of the hyporheic zone was $0.95 \mathrm{~m}$ in the location where the maximum hyporheic flux occurred based on the gradient of $0.01{ }^{\circ} \mathrm{C} / \mathrm{m}$, as illustrated in Fig. $6(\mathrm{~b})$. Similarly, the maximum depth of hyporheic zone was $2.95 \mathrm{~m}$ in the location where the minimal hyporheic flux occurred based on the first standard as illustrated in Fig. 6(c). The above was associated with the conclusion that the larger the hyporheic flux, the smaller the depth of the hyporheic zone. The temperature of groundwater ranged from 20 to $24^{\circ} \mathrm{C}$, which was approximately $10^{\circ} \mathrm{C}$ below surface water temperature.

\section{CONCLUSIONS}

This study calculated hyporheic flux based on the governing equation for one-dimensional steadystate heat transport with the direction of groundwater discharge via a heat tracing method. There were major discharge zones in the measured profiles. The hyporheic flux had spatial heterogeneity, 

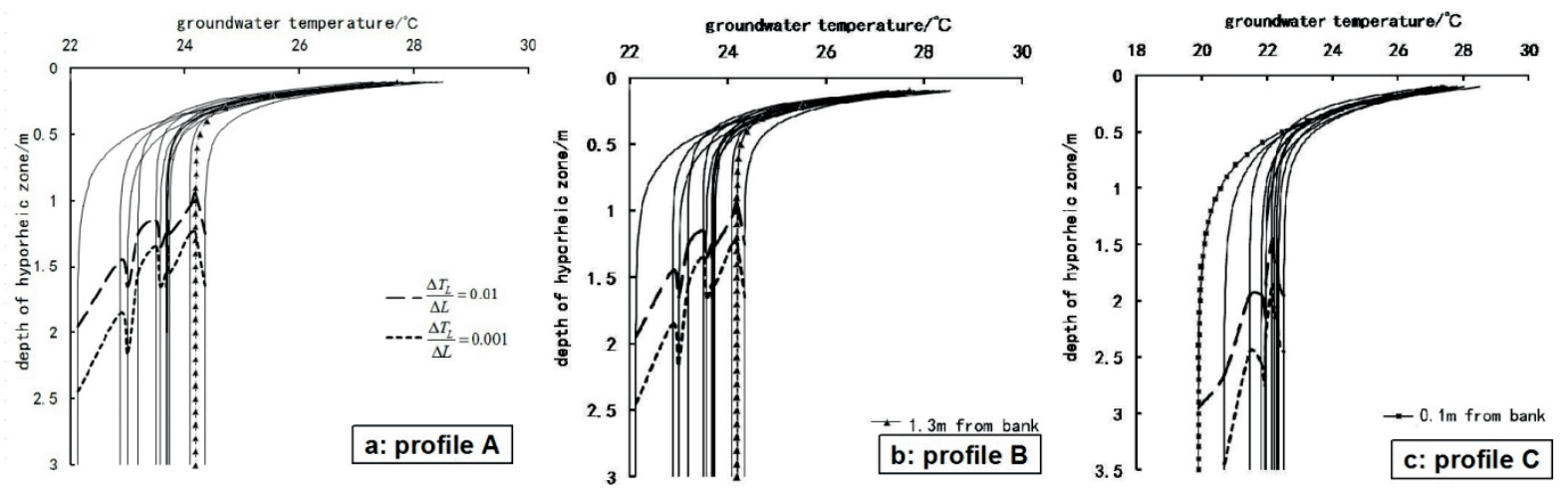

Fig. 6 Hyporheic zone depths and groundwater temperatures relation curves.

and the heterogeneity within the river was more remarkable than the riverbank, which confirmed the validity of studying heterogeneity of hyporheic flux via heat tracing method.

The high discharge zones determined by low temperature zones of the observed streambed temperature profiles were in line with big flux zones calculated from analytical solutions.

The depth of the hyporheic zone was inversely proportional to the hyporheic flux. The bigger the hyporheic flux, the smaller the depth of the hyporheic zone. The range of the hyporheic zone depth was controlled by the heterogeneity of the magnitude of hyporheic flux.

Acknowledgements This research was supported by the National Natural Science Foundation of China (grant 41201029), China Postdoctoral Science Foundation (2013M540410), and National Undergraduate Training Programs for Innovation (201410294004).

\section{REFERENCES}

Anderson, M. (2005) Heat as a ground water tracer. Ground Water 43, 951-968.

Bredehoeft, J. and Papadopolus, I. (1965) Rates of vertical groundwater movement estimated from the Earth's thermal profile. Water Resources Research 1(2), 325-328.

Brunke, M. and Gonser, T. (1997) The ecological significance of exchange processes between rivers and groundwater. Freshwater Biology 37, 1-33.

Conant Jr, B. (2004) Delineating and quantifying ground water discharge zones using streambed temperatures. Ground Water $42,243-257$.

Ferguson, G. (2007) Heterogeneity and thermal modeling of ground water. Ground Water 45, 485-490.

Harvey, J. and Bencala, K. (1993) The effect of streambed topography on surface-subsurface water exchange in mountain catchments. Water Resources Research 29(1), 89-98.

Hatch, C., et al. (2006) Quantifying surface water- ground water interactions using time series analysis of streambed thermal records. Water Resources Research 42, W10410.

Kalbus, E., et al. (2006) Measuring methods for groundwater - surface water interactions a review. Hydrology and Earth System Sciences 10, 873-887.

Lautz, L. et al. (2010) Heat tracing of heterogeneous hyporheic exchange adjacent to in-stream geomorphic features. Hydrological Processes 24, 3074-3086.

Schmidt, C., et al. (2006) Characterization of spatial heterogeneity of groundwater-stream water interactions using multiple depth streambed temperature measurements at the reach scale. Hydrology and Earth System Sciences, 10, 849-859.

Stonestrom, D. and Constantz, J. (2003) Heat as a tool for studying the movement of ground water near streams. US Geological Survey Circular 1260, 86.

Wang, W., et al. (2007) Evolution of the relationship between river and groundwater and several scientific problems. Journal of Jilin University (Earth Science Edition) 37(2), 231-238. 